
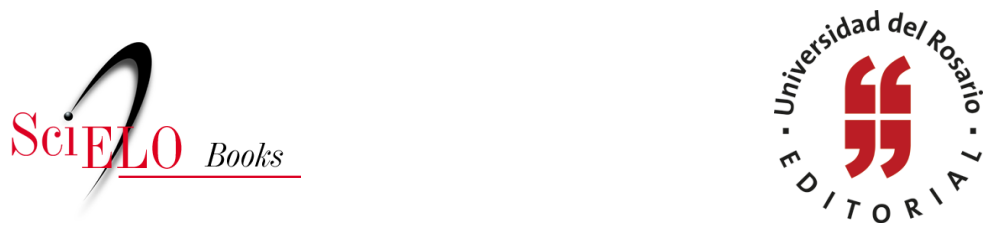

\title{
Estudio previo para los lineamientos de una propuesta de política cultural en la Universidad del Rosario
}

\author{
Ramón E. Villamizar Maldonado
}

\section{SciELO Books / SciELO Livros / SciELO Libros}

VILLAMIZAR MALDONADO, R.E. Estudio previo para los lineamientos de una propuesta de política cultural en la Universidad del Rosario. In: DÍAZ TÁMARA, A., and GUZMÁN BEJARANO, M., eds. Proceso de construcción de la política cultural en la Universidad del Rosario [online]. Bogotá: Editorial Universidad del Rosario, Decanatura del Medio Universitario, 2014, pp. 43-77. ISBN: 978-958-738-541-0. https://doi.org/10.7476/9789587385410.0003.

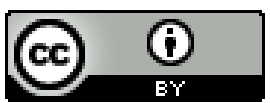

All the contents of this work, except where otherwise noted, is licensed under a Creative Commons Attribution 4.0 International license.

Todo o conteúdo deste trabalho, exceto quando houver ressalva, é publicado sob a licença Creative Commons Atribição 4.0.

Todo el contenido de esta obra, excepto donde se indique lo contrario, 


\title{
Estudio previo para los lineamientos de una propuesta de política cultural en la Universidad del Rosario
}

\author{
Ramón E. Villamizar Maldonado*
}

La Decanatura del Medio Universitario desarrolló un estudio previo con el objetivo de establecer lineamientos para construir una política cultural en la Universidad del Rosario. Este estudio se desarrolló durante el periodo comprendido entre el 2009 y 2011 con la asesoría de Ramón E. Villamizar Maldonado y se plasmó en el documento que presentamos a continuación.

\section{Fortalecimiento de la proyección del medio universitario. Eje cultural}

\section{El rol de la cultura en el fortalecimiento de la proyección del}

\section{Medio Universitario y como eje cultural de la Universidad}

\section{Promotora de Salud}

El proceso formativo y educativo de la Universidad es esencialmente un proyecto cultural. La cultura, entendida "como conjunto de actitudes, creencias, convenciones, costumbres, valores y prácticas compartidas o comunes", es el sustrato de la vida universitaria y por ende define en gran medida el educative

* Politólogo por la Universidad de los Andes, especialista en Gobierno y Políticas Públicas, docente de la Especialización en Gerencia y Gestión Cultural de la Universidad del Rosario. 
medium que educa tanto como el currículo. ${ }^{1}$ La vida universitaria entonces se juega también en el terreno de las representaciones y lo simbólico y es un espacio rico en prácticas artísticas, patrimoniales y en expresiones culturales.

Precisamente un primer rasgo de la Universidad del Rosario es su patrimonio cultural que es legado del pasado y define en gran medida la manera de experimentar la vida universitaria. En sus 360 años de historia la Universidad del Rosario ha funcionado en el conjunto arquitectónico del Claustro, que comprende la capilla de Nuestra Señora del Rosario "La Bordadita" y una "colección de arte conformada por 243 obras pictóricas", ${ }^{2}$ esculturas y orfebrería, así como el archivo histórico. Igualmente hace parte de dicho patrimonio cultural la definición que de ella hiciera su fundador, los símbolos, las instituciones como la colegiatura, la consiliatura, el juramento de grado, los diplomas y el legado de los personajes y exalumnos destacados. ${ }^{3}$

La Universidad es también un espacio fecundo para las expresiones artísticas y culturales; muestra de ello es la existencia de múltiples grupos artísticos institucionales, espacios de circulación permanente como exposiciones, festivales de música, coros, danza, teatro, para citar solo algunos. También, la Universidad es diversa al tener un indicador del alto porcentaje de estudiantes que provienen de fuera de Bogotá. Existen criterios especiales para la admisión de estudiantes indígenas

1 UNIVERSIDAD DEL ROSARIO. Fortalecimiento de la Proyección del Medio Universitario. Universidad Promotora de Salud. Documento de trabajo 4 , p. 3 y 8.

2 GIL MARÍN, Javier. El arte en el Colegio Mayor de Nuestra Señora del Rosario. Tesoros del Colegio Mayor de Nuestra Señora del Rosario, 350 años. Bogotá: Villegas Editores, 2003, p. 73.

3 DECANATURA DEL MEDIO UNIVERSITARIO. Cartilla de apoyo a la formación rosarista. Bogotá: Universidad del Rosario, 2010. 
y afrocolombianos, así como para estudiantes en condiciones de discapacidad.

La dimensión cultural del medio universitario es fundamental para la formación integral que, tal como lo define el PEI, es el objetivo central de la acción educativa ${ }^{4}$ y que comprende "todos los aspectos de la persona humana, como ser racional y social, tanto en sus aspectos espirituales, culturales e intelectuales, como en los relacionados con su desempeño físico. Se expresa, además, en la ética, que constituye el eje articulador de todos los procesos formativos". ${ }^{5}$

Precisamente como parte de los compromisos con el Plan Integral de Desarrollo (2004-2019) en el Eje Consolidación de la Identidad y la Comunidad Rosaristas, la Decanatura del Medio Universitario viene trabajando de manera concertada con otras unidades académicas y administrativas en un documento que definirá la manera de cumplir el objetivo de "fortalecer la proyección del Medio Universitario, a través de la inserción de políticas, estrategias, programas y líneas de acción cuyo foco esté puesto en el concepto de Universidad Saludable". ${ }^{6}$ El documento presenta un desplazamiento del concepto de Universidad Saludable hacia el de Universidad Promotora de Salud, que se considera más integral y define como medios para su implementación cuatro ejes con sus respectivas políticas, programas y proyectos. ${ }^{7}$

4 UNIVERSIDAD DEL ROSARIO. Proyecto Educativo Institucional (PEI). Bogotá: Editorial Universidad del Rosario, 2010, p. 8 y 9.

5 Ibid., p. 28.

6 UNIVERSIDAD DEL ROSARIO. Plan Integral de Desarrollo 20042019. Actualización 2009, p. 63 y 64.

7 UNIVERSIDAD DEL ROSARIO. Área de Formación y Desarrollo Humano. Propuesta para el Proyecto de Universidad Saludable. Documento borrador. Marzo 18 de 2010. 
El Eje Cultural, a través de la política cultural, parte del reconocimiento de la cultura en el fortalecimiento del medio universitario y como el espacio en "donde se escenifican las transformaciones en los hábitos y modos de vida" ${ }^{8}$ de las personas que componen la comunidad universitaria. Este planteamiento define para la cultura un rol estratégico en la apropiación de los pilares sobre los cuales descansa la propuesta de Universidad Promotora de Salud, es decir un concepto de la salud definido como "un completo estado de bienestar físico, mental y social”, y un concepto de promoción, concebida "como la suma de las acciones de la población, los servicios de salud, las autoridades sanitarias y otros sectores sociales y productivos, encaminados al desarrollo de mejores condiciones de salud individual y colectiva". ${ }^{9}$ Pero también el bienestar implica generar condiciones para el desarrollo de la creatividad y las prácticas artísticas, patrimoniales y las expresiones culturales de estudiantes, docentes, trabajadores y egresados.

\section{Política cultural en la Universidad del Rosario}

\section{Contexto y antecedentes}

La Universidad del Rosario cuenta con $12.923^{10}$ estudiantes matriculados en pregrado y postgrado, siendo la población femenina el $60 \%$ del total. El cuerpo de profesores es de 1310 aproximadamente y en aspectos administrativos trabajan 608 personas. El número de egresados también ha crecido y hoy en

8 InSTItUTO Distrital DE CULTURA Y TURISMO. Políticas culturales distritales 2004-2016. Bogotá: IDCT, 2004, p. 9.

9 OPS/OMS, 1990.

10 UNIVERSIDAD DEL ROSARIO. Boletín estadístico 2009. Bogotá: Universidad del Rosario, p. 15. 
día en las bases de datos de la Universidad se tienen identificados cerca de 15.000 profesionales rosaristas. En consecuencia, la Universidad es un espacio diverso y rico con respecto a orígenes, estilos de vida, expresiones culturales y costumbres. Igualmente, es un espacio para recrear la memoria cultural y el patrimonio de la nación representado en el Rosario.

Son varias las unidades administrativas y académicas que desarrollan acciones en relación con la cultura, así como son variadas las percepciones que circulan entre los diferentes grupos de la comunidad universitaria sobre el rol del arte y la cultura en el proyecto universitario.

\section{Estructura, responsables y funciones}

Como se anotaba anteriormente la acción cultural en la Universidad no se encuentra centralizada y en ella intervienen activamente varias dependencias.

\section{Vicerrectoría}

La Vicerrectoría lidera "la política institucional académica de la Universidad en materia de investigación, docencia y extensión". ${ }^{11}$ Para el caso que nos ocupa, de ella dependen: la Cancillería, que maneja la internacionalización de la Universidad; la Biblioteca, la Editorial, la Revista del Rosario y las unidades académicas, entre ellas las siete Facultades y la Decanatura del Medio Universitario. En el año 2007 se creó la Dirección de Extensión como dependencia adscrita a la Vicerrectoría.

La Cancillería coordina el programa de Internacionalización en Casa que es el conjunto de "estructuras políticas, procesos y acciones que fortalecen la internacionalización desde el mismo ámbito de la Universidad del Rosario, fortaleciendo así

11 Ver: www.urosario.edu.co/directivas 6 de noviembre de 2009. 
las oportunidades de enseñanza-aprendizaje de la comunidad académica" ${ }^{12} \mathrm{El}$ programa actúa en tres ámbitos: internacionalización del currículo, multilingüismo y multiculturalismo.

La Decanatura del Medio tiene bajo su responsabilidad las acciones culturales más visibles puesto que tiene a su cargo el bienestar universitario de los estudiantes y es la dependencia que "orienta sus programas y servicios a la formación integral del estudiante como eje fundamental que abarca todos los aspectos de la persona humana, en su ser racional y social, en sus aspectos espirituales, culturales, intelectuales y psicológicos y en lo relacionado con su desarrollo físico". ${ }^{13}$

La Dirección de Extensión fue creada en 2007 y su misión es:

Ser el área articuladora de las tres funciones sustantivas (docencia, investigación y extensión) vinculando el conjunto de saberes desarrollados en las mismas con las Empresas, el Estado y la Comunidad y mediante la prestación de servicios que se caractericen por su pertinencia, innovación, impacto social, que sean sostenibles económica y socialmente y logren posicionar y visibilizar la función sustantiva, todo ello en procura de contribuir a tener una sociedad incluyente en lo social, más eficiente en lo empresarial y más competitiva en términos generales.

12 UNIVERSIDAD DEL ROSARIO. Eje de Internacionalización en Casa. Informe tercera semana internacional. Septiembre 21 al 29 de 2009. Bogotá: Cancillería de la Universidad del Rosario, 2009, p. 1.

13 UNIVERSIDAD DEL ROSARIO, DECANATURA DEL MEDIO UNIVERSITARIO. Informe de gestión 2008. Bogotá: Universidad del Rosario, 2009. Documento inédito. 
La gestión cultural hace parte de las áreas de intervención puesto que es un aspecto fundamental de la relación de la Universidad con su entorno inmediato y con las políticas culturales nacionales y distritales.

\section{Sindicatura}

La Sindicatura, a través de la Dirección de Servicios Administrativos, se encarga de la gestión logística y de la infraestructura de planta física, recursos físicos y de seguridad. ${ }^{14}$ Esta dependencia es la responsable de las intervenciones en las diferentes sedes. También dentro de sus responsabilidades están las relaciones con el personal de apoyo administrativo a través de la Dirección Administrativa y de Tecnología y su Departamento de Desarrollo Humano. Allí "el área de bienestar tiene como propósito definir, diseñar y ejecutar programas que se orienten a la construcción de un escenario laboral adecuado, creando una identificación clara entre el empleado y la comunidad rosarista. De esta forma, se fortalece el sentido de pertenencia, la calidad de vida del empleado y el compromiso con la institución”. Los programas que desarrolla son: clima laboral (encuestas para establecer la satisfacción de las personas en este aspecto) y actividades recreativas y culturales (se desarrollan en conjunto con las cajas de compensación familiar, así como programas de turismo nacional e internacional, subsidios de vivienda y educativo).$^{15}$ Igualmente, de la Sindicatura depende la gerencia comercial y de mercadeo que se encarga del posicionamiento, manejo

14 Ver: www.urosario.edu.co/FASE2/otros_servicios/otrosservicios_misio_vision.htm 24 de noviembre de 2009.

15 Ver: www.urosario.edu.co/FASE2/personal_administrativo/persoadmin_dptodesarrollohumano 22 de noviembre de 2009. 
de la imagen y marca de la Universidad y de las estrategias de divulgación y comunicación.

\section{Secretaría General}

La Secretaría General, entre otras responsabilidades, tiene a su cargo velar por la conservación y restauración del patrimonio cultural mueble, inmueble y documental de la Universidad, que incluye el Claustro y la capilla de La Bordadita, la pinacoteca, el Archivo Histórico y otros bienes muebles de importancia cultural. En el año 2010 fue creada la Unidad de Patrimonio Histórico precisamente para centralizar la gestión y manejo del patrimonio inmueble y mueble de la Universidad.

\section{Aproximación a las acciones culturales}

en la Universidad y principales resultados

Las acciones desarrolladas son de diferente naturaleza e inicialmente se propone agruparlas de la siguiente manera: formación artística y cultural a través del currículo y de los "grupos institucionales"; servicios de bibliotecas; editorial y publicaciones; protección y salvaguardia del patrimonio cultural; acciones afirmativas y de reconocimiento de la diversidad cultural; realización de eventos artísticos y culturales (festivales, conciertos, exposiciones, presentaciones), entre otras.

\section{Formación cultural y artística a través del currículo}

Dentro de los currículos de los distintos programas académicos que ofrece la Universidad, las asignaturas electivas buscan favorecer el desarrollo de competencias adicionales a las relacionadas con los programas académicos y son consideradas como esenciales para la formación integral de los estudiantes. En el segundo periodo académico de 2005 la Universidad realizó una 
revisión profunda a los programas de pregrado e introdujo el núcleo de formación rosarista.

El núcleo de formación rosarista busca aportar a "la formación ética y en valores" de los estudiantes y a que los profesionales egresados sean versátiles, polivalentes, respetuosos "de la diversidad y de la realidad multicultural del país, con comprensión de la dimensión intercultural en un mundo globalizado, con conocimientos sólidos en lo fundamental, con competencias para aprender a lo largo de toda la vida y con claridad sobre la necesidad de actualizarse permanentemente". ${ }^{16}$ Los componentes del núcleo de formación rosarista son siete, ${ }^{17}$ de los cuales tres tienen claramente relación con la cultura: cultura y cátedra rosarista, ${ }^{18}$ dimensión internacional, intercultural y global, ${ }^{19}$ y formación humanista, cultural, artística y para el desarrollo físico.

16 UNIVERSIDAD DEL ROSARIO. Núcleo de formación rosarista. Documento inédito. Pp. 2-3.

17 "Cultura y cátedra rosarista"; "Formación ética y en valores"; "Desarrollo de competencias básicas para el aprendizaje superior"; "Cátedra Colombia"; "Formación para la docencia, la investigación y otros intereses", para la aproximación y compromiso con la realidad nacional e intercultural y al manejo de lenguas extranjeras.

18 "Cultura Rosarista consiste en un módulo obligatorio de cultura rosarista para todos los estudiantes en el primer semestre con intensidad de doce horas, no tiene valor en créditos pero el cumplimiento de esta actividad será prerrequisito para la inscripción en el segundo período académico. La Cátedra Rosarista está orientada a profundizar en la historia, legados y proyección de la Universidad del Rosario y al estudio interdisciplinario de temas de interés prioritarios para el país. Tiene una valoración de dos créditos y para los estudiantes es obligatorio tomar una dentro de la oferta realizada" (ibid., p. 4).

19 Incluye la enseñanza del inglés como segunda lengua, otros idiomas y cultura internacional. La institución propicia un nivel de internacionalización de su comunidad académica para que pueda asumir las actuales realidades del contexto local y global, en pos de una sociedad que difunda 
La Decanatura del Medio Universitario y la Escuela de Ciencias Humanas presentan dentro de su oferta académica asignaturas que los estudiantes deben cursar ya sea de manera obligatoria o, según sus intereses, como electivas en el plan de estudios. Si bien otras Facultades vienen incluyendo asignaturas relacionadas con el arte y la cultura en sus programas de estudio, son estas dos las que tienen la mayor oferta según está registrado en el cuadro 1 y cuadro 2.

\section{Cuadro 1. Electivas relacionadas con Arte, Cultura y Patrimonio}

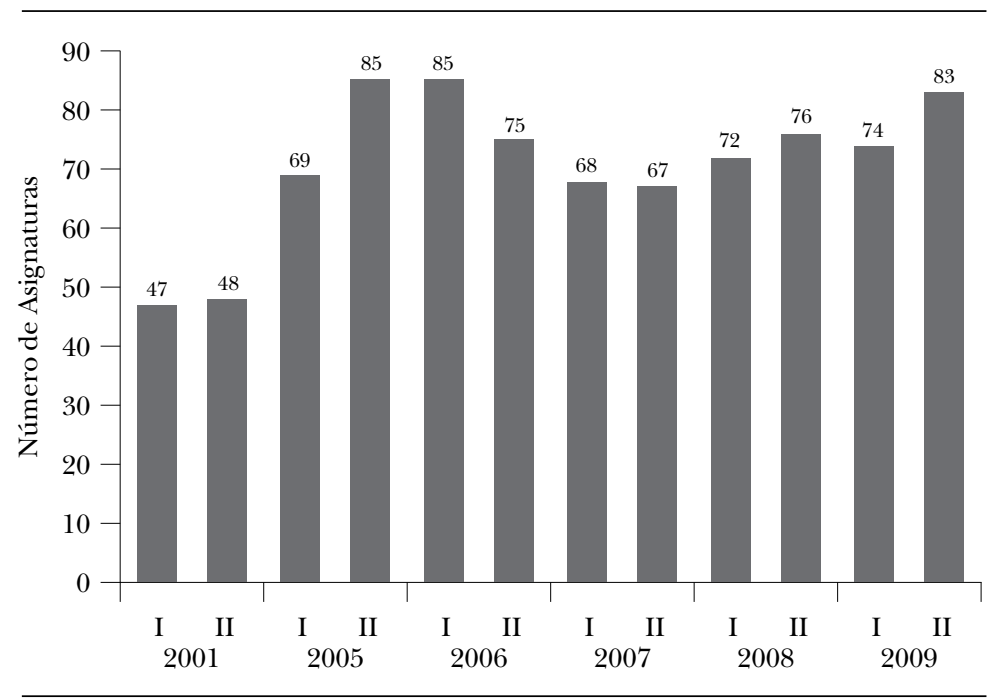

y promueva valores interculturales más solidarios y equitativos e inserte a la Universidad en el concierto mundial de la educación superior de cara al siglo XXI. 


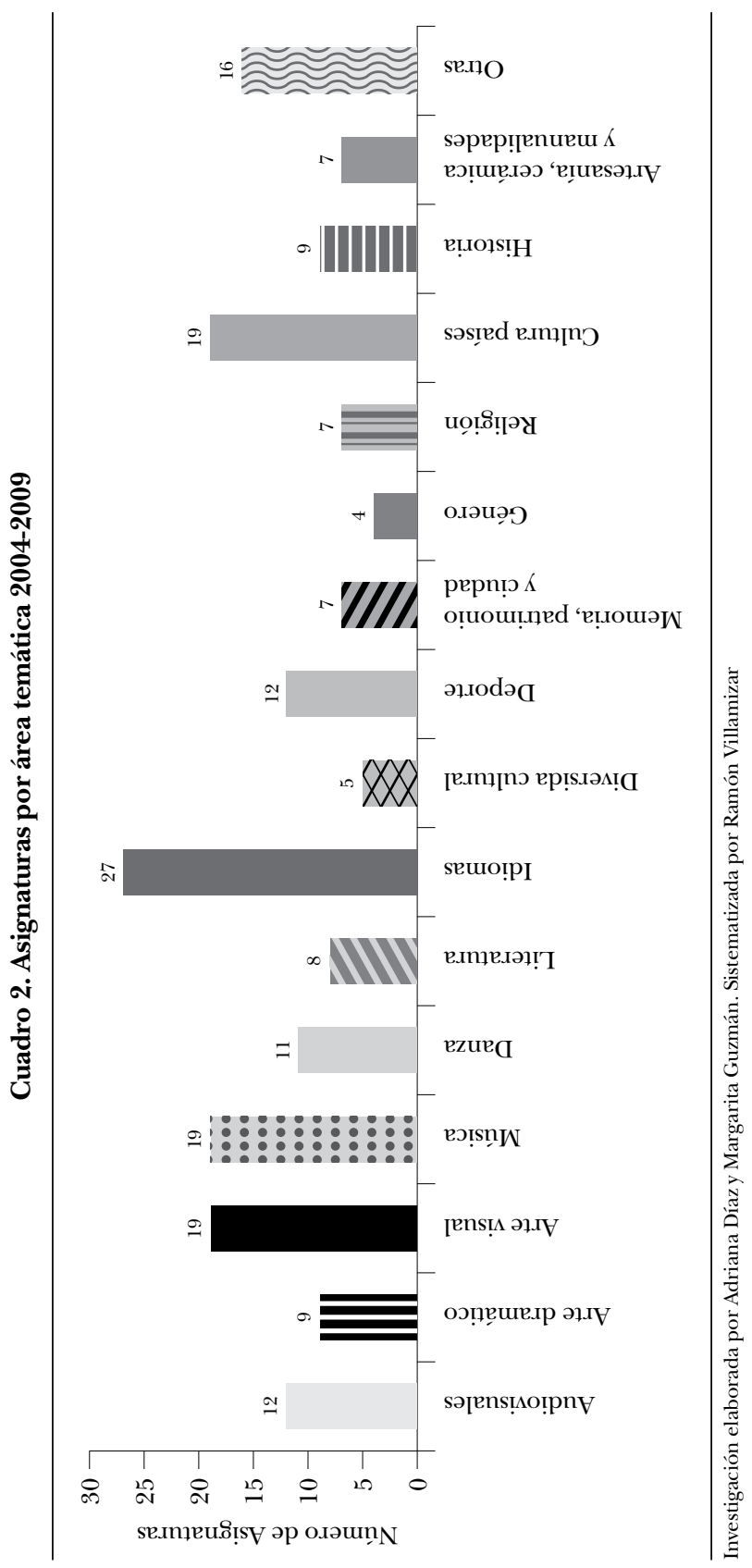




\section{Formación artística través de los "grupos institucionales"}

La actividad de los grupos institucionales está encaminada a apoyar el proceso de formación integral de los estudiantes de la Universidad, generar espacios de participación e integración de los miembros de la comunidad, favorecer la construcción de ciudadanía y liderazgo, permitir el desarrollo de talentos, destrezas y habilidades e incentivar el sentido de pertenencia a la Institución.

Cuadro 3. Grupos artísticos institucionales y estudiantes participantes

\begin{tabular}{|l|r|r|r|r|r|r|r|}
\hline \multicolumn{1}{|c|}{ Grupos } & 2004 & 2005 & 2006 & 2007 & 2008 & 2009 & 2010 \\
\hline Coro & 18 & 25 & 29 & 33 & 23 & 21 & 16 \\
\hline Danza árabe & & & 8 & 11 & 10 & 34 & 13 \\
\hline Danza contemporánea & 11 & 9 & 5 & 8 & 7 & 11 & 10 \\
\hline Danza folclórica & 17 & 12 & 18 & 21 & 21 & 8 & 9 \\
\hline Capoeira & & & & 13 & 13 & 24 & 15 \\
\hline Salsa y ciudad & & & & & 28 & 17 & 20 \\
\hline Tango & & 12 & 13 & 9 & 6 & 18 & 8 \\
\hline Teatro & 19 & 10 & 8 & 10 & 10 & 18 & 12 \\
\hline Tuna & & & 21 & 26 & 25 & 26 & 39 \\
\hline Total & 65 & 68 & 102 & 131 & 143 & 138 & 142 \\
\hline
\end{tabular}

Los grupos institucionales realizan presentaciones (circulación) en festivales, circuitos interuniversitarios, locales, distritales y nacionales. En el año 2009 realizaron trece presentaciones.

\section{Sistema de Bibliotecas}

La Biblioteca presta servicios asociados a la compra, circulación, préstamo de material bibliográfico, gráfico y audiovisual. 
También realiza acciones de capacitación en el manejo de estos servicios. El sistema de bibliotecas está conformado por la Biblioteca Antonio Rocha Alvira (colecciones de Jurisprudencia, Economía, Administración de Empresas y Ciencias Humanas y Sociales); la Biblioteca de Ciencias de la Salud, Biblioteca Hospital Universitario Mayor y Biblioteca Sede Norte. Al sistema pueden acceder los estudiantes, docentes, egresados y personal administrativo. El público en general puede ser usuario siempre y cuando cumpla con algunos requisitos.

Cuadro 4. Entrada de usuarios a la Biblioteca

\begin{tabular}{|l|r|r|r|r|}
\hline \multicolumn{1}{|c|}{ Sede } & 2006 & 2007 & 2008 & 2009 \\
\hline Claustro & 520.158 & 586.276 & 691.012 & 599.835 \\
\hline Quinta de Mutis & 299.104 & 337.973 & 361.040 & 338.270 \\
\hline $\begin{array}{l}\text { Hospital } \\
\text { Universitario }\end{array}$ & na & na & 9877 & 39.933 \\
\hline Nueva sede & na & na & na & 6436 \\
\hline Total & 819.262 & 924.249 & 1.061 .929 & 984.474 \\
\hline
\end{tabular}

Boletín Estadístico 2009, p. 122.

\section{Editorial y publicaciones}

La Editorial de la Universidad busca producir y reproducir "bienes para venta e intercambio", ${ }^{20}$ en este caso de obras protegidas por derechos de autor, lo que la define como una empresa o industria cultural. Su misión es "publicar textos producto de la labor científica y docente”.

20 THROSBY, David. Economía y cultura. Madrid: Cambridge University Press, 2001, p. 126. 


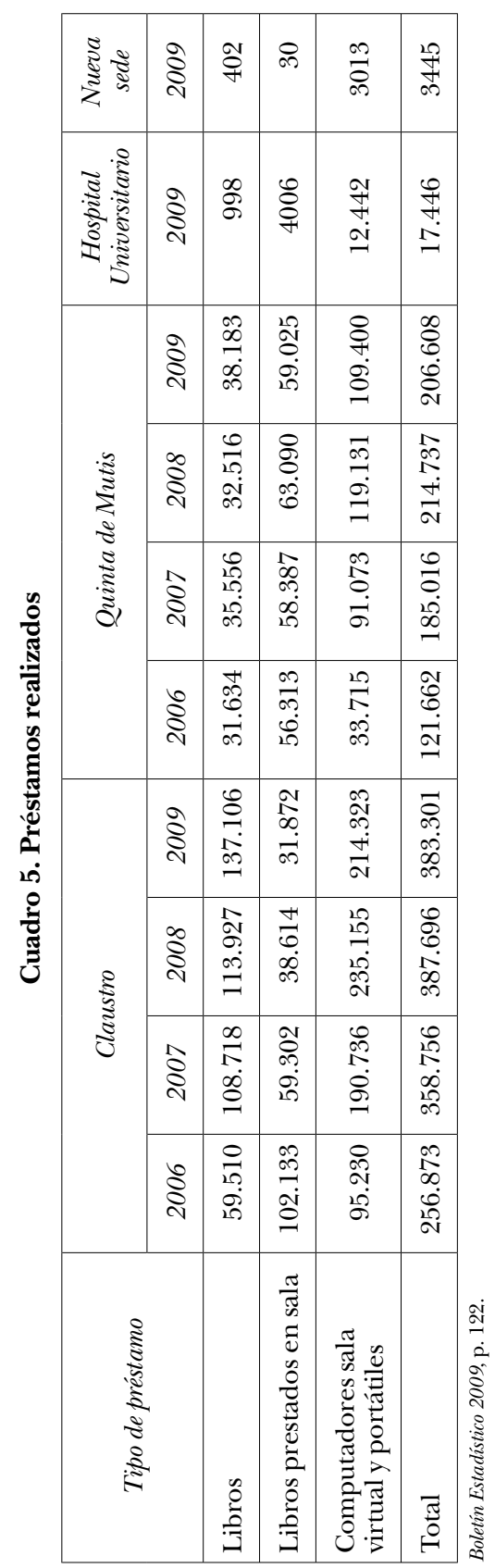


Cuadro 6. Libros y documentos publicados por la Editorial

\begin{tabular}{|l|c|c|c|c|c|c|}
\cline { 2 - 7 } \multicolumn{1}{c|}{} & 2005 & 2006 & 2007 & 2008 & 2009 & Total \\
\hline Libros & 34 & 64 & 68 & 81 & 98 & 345 \\
\hline $\begin{array}{l}\text { Documentos o borradores } \\
\text { de investigación }\end{array}$ & 65 & 62 & 60 & 62 & 53 & 302 \\
\hline Total & 99 & 126 & 128 & 143 & 151 & 647 \\
\hline
\end{tabular}

\begin{tabular}{|c|c|}
\hline \multicolumn{2}{|c|}{ Libros coeditados } \\
\hline 2008 & 2009 \\
\hline 13 & 15 \\
\hline
\end{tabular}

Cuadro 7. Revistas científicas publicadas por la Editorial Universidad del Rosario

\begin{tabular}{|l|c|c|c|c|c|c|}
\hline Facultad/unidad & 2005 & 2006 & 2007 & 2008 & 2009 & Total \\
\hline $\begin{array}{l}\text { Cienca Política y R. } \\
\text { Internacionales }\end{array}$ & 2 & 3 & 3 & 4 & 5 & 17 \\
\hline Economía & 2 & 2 & 2 & 2 & 2 & 10 \\
\hline $\begin{array}{l}\text { Escuela de Ciencias } \\
\text { Humanas }\end{array}$ & 0 & 0 & 0 & 0 & 0 & 0 \\
\hline Administración & 2 & 2 & 2 & 2 & 2 & 10 \\
\hline Jurisprudencia & 3 & 2 & 3 & 3 & 3 & 14 \\
\hline Medicina y Rehabilitación & 2 & 2 & 4 & 3 & 4 & 15 \\
\hline Rectoría & 1 & 2 & & & & 3 \\
\hline Total & 12 & 13 & 14 & 14 & 16 & 69 \\
\hline
\end{tabular}

Boletín Estadístico 2009, p. 117.

Entre las publicaciones se destaca la revista del Rosario Nova et Vetera, que fue creada en 1905 como "órgano de difusión del pensamiento, de la historia, la investigación y las inquietudes tanto de los docentes y directivos de la Universidad, como de nuestros colegas amigos, egresados y estudiantes que deseen 
compartir sus puntos de vista con el país". ${ }^{21}$ Hasta el momento han circulado 600 números y cuenta con un tiraje de 13.000 ejemplares.

El periódico denominado Nova et Vetera circula quincenalmente de manera gratuita y combina secciones informativas sobre diferentes aspectos de la vida universitaria con secciones de opinión. Fue creado hace cuatro años y circulan dieciocho números por año, con un tiraje de 9000 ejemplares por edición. ${ }^{22}$

Ahora, en relación con los contenidos de estas últimas publicaciones se ha encontrado que a su vez el arte y el patrimonio son abordados de manera especializada a través de editoriales, reportajes y artículos.

\section{Acciones de protección, salvaguardia, investigación y divulgación del patrimonio cultural ${ }^{23}$}

El claustro donde funciona la Universidad del Rosario desde 1653 es un símbolo arquitectónico colonial que se encuentra en el centro histórico y cultural de Bogotá, y está ubicado en la calle 14, que fue llamada Calle de Pueblo Viejo, la cual aparece como la más antigua de la capital. ${ }^{24}$ Fue declarado monumento

${ }^{21}$ Ver: www.urosario.edu.co/revista/index.htm 6 de noviembre de 2009 .

22 Información suministrada por el Departamento de Comunicaciones a Karol Hernández.

23 Este aparte contó con los aportes de Margarita Guzmán Bejarano y de su proyecto de grado "MURo: Museo Universitario del Rosario, posibilidad y proyección” de la maestría en Museología y Gestión del Patrimonio.

24 Ver: http://www.urosario.edu.co/FASE4/web_visitantes/sombolos_claustro.htm noviembre 4 de 2009, 11.00 pm. "El Claustro es la sede principal de la Universidad del Rosario y fue construida en la época de la Colonia bajo el estilo Escolar del siglo Xviı por Fray Cristóbal de Torres su fundador. La entrada es enmarcada por un antiguo portón verde, desde donde se puede contemplar la imponente estatua del Fundador, erigida en 
nacional a través del decreto 1584 de 1975 . Como parte del conjunto se destaca la capilla de La Bordadita que es "quizás uno de los espacios mejor conservados en su originalidad arquitectónica del siglo xvII". ${ }^{25}$

Con relación a los bienes muebles, desde su fundación y durante la época de la colonia, se fomentó la colección de arte conformada actualmente por 243 obras muy significativas. ${ }^{26}$ Se trata de retratos al óleo de los rectores de la universidad y de personajes notables que constituyen un testimonio de la historia de nuestra nación y de la historia del arte colombiano desde el siglo XVII hasta la actualidad. ${ }^{27}$ Esta colección posee, además, cuadros religiosos, esculturas y orfebrería, así como un

bronce por el escultor catalán Dionisio Renart y García en 1909. Actualmente el Claustro es considerado patrimonio cultural nacional. Este hito urbano por excelencia ha preservado a lo largo de estos tres siglos su estructura de arquería y columnas, aunque fue considerablemente alterado en el siglo xix. En esta edificación de dos pisos se destacan las obras de arte, las placas evocadoras de héroes, magistrados y poetas, como testimonio de la historia del Rosario. El Aula Máxima, lugar donde se celebran las principales ceremonias, es una de las mejores pinacotecas colombianas y guarda imágenes preciosas de estos siglos producidas por los más preclaros pinceles de la patria”.

25 DECANATURA DEL MEDIO AMBIENTE. Cartilla de apoyo a la información rosarista. Bogotá: Universidad del Rosario, 2010.

26 GIL MARÍN, Javier. El arte en el Colegio Mayor de Nuestra Señora del Rosario. Tesoros del Colegio Mayor de Nuestra Señora del Rosario, 350 años. Bogotá: Villegas Editores, 2003, p. 73.

27 "En 176 retratos de los personajes ilustres y cuadros religiosos se manifiesta la historia de la nación y del arte colombiano, en la medida que más de treinta artistas reconocidos han sido identificados como autores de las obras de la colección. Entre ellos se cuentan Gregorio Vásquez de Arce y Ceballos, Gaspar de Figueroa, Baltasar de Figueroa, Joaquín Gutiérrez el pintor de los virreyes, Ricardo Acevedo Bernal, Luis García Hevia y Andrés de Santamaría” (Guzmán Bejarano, op. cit.). 
archivo histórico imponderable considerado como un valioso patrimonio documental para el país. ${ }^{28}$

En la publicación realizada por la Decanatura del Medio Universitario Historia y tradición de la Universidad del Rosario se resaltan aquellos aspectos que pueden considerarse como parte del patrimonio intangible de la Universidad, el cual se divulga en el taller de Cultura Rosarista y en las cátedras rosaristas.

En relación con el Claustro, permanentemente se desarrollan acciones que buscan su protección y conservación, coordinadas por la Secretaría General con cargo al presupuesto de inversión de la Universidad y con la asesoría de especialistas en restauración y manejo de bienes de interés cultural. Desde 2010 estas funciones fueron trasladadas a la Unidad de Patrimonio Histórico adscrita a la Secretaría General.

La apropiación de este patrimonio cultural por parte de la comunidad universitaria resulta fundamental y por ello se vienen desarrollando acciones desde el currículo a través del núcleo de formación rosarista; el taller de Cultura Rosarista que incluye visitas guiadas al Claustro y la pinacoteca; exposiciones y diversas publicaciones en la Revista del Rosario y en el periódico Nova et Vetera.

También es importante la línea de historia de la Universidad, conformada por profesores e investigadores, que realiza investigaciones y publicaciones sobre la memoria y el patrimonio intangible de la Universidad. Sobresale la colección de dieciocho tomos sobre la historia de la Universidad en donde se destacan trabajos sobre la comida en la universidad, los bienes urbanos y rurales, la medicina, entre otros.

Con relación a el patrimonio documental, el Archivo Histórico funciona como una unidad especializada en la

\footnotetext{
28 Ibid.
} 
conservación, restauración y gestión del mismo. Su acervo se encuentra microfilmado y está compuesto por "todos los documentos relacionados con la historia de la institución (...). El documento más antiguo data del año 1646. (...) Se guarda además la librería antigua, cuyo libro más antiguo es un incunable que data del año $1474 "{ }^{29}$

\section{Acciones afirmativas y de reconocimiento de la diversidad cultural}

La Universidad comprende y reconoce la diversidad cultural desde varios puntos de vista. El primero tiene que ver con el origen de los estudiantes matriculados que provienen de fuera de Bogotá y de los estudiantes extranjeros, cuyo número ha venido creciendo. Una segunda mirada tiene que ver con las acciones para facilitar el acceso a la universidad a personas pertenecientes a comunidades afrodescendientes, pueblos indígenas y a la población en condición de discapacidad.

Finalmente, el aspecto espiritual y religioso de la diversidad tiene en la Universidad al Centro de Estudios Teológicos y de las Religiones (CETRE), creado en 2005 y cuyo objetivo es "proporcionar una formación teológica en la fe, así como el estudio de las implicaciones sociales políticas y culturales del fenómeno religioso y la oportunidad de encuentros enriquecedores y respetuosos a nivel ecuménico y macroecuménico". ${ }^{30}$ Ofrece asignaturas electivas tales como "Diversidad religiosa y libertad de cultos", "Conflictos internacionales y religión”, "Entornos económicos globales y las religiones", "Islam y fundamentalismo religioso", "La religión en el cine", entre otros. Tiene varias

29 DECANATURA DEL MEDIO UNIVERSITARIO. Cartilla de apoyo a la información rosarista. Bogotá: Universidad del Rosario, 2010.

30 Ver: www.urosario.edu.co/cetre/index.html 16 de noviembre de 2009 . 
líneas de investigación ("semilleros de investigación") en teología luterana, islam, teología bíblica y en protestantismo. Algunas Facultades como la de Jurisprudencia han creado espacios de formación y reflexión como la "Cátedra Viva Intercultural", asignatura electiva que tiene gran acogida entre los estudiantes.

\section{Funciones de Extensión}

De acuerdo con los lineamientos institucionales, en el año 2008 se establecieron "las áreas de influencia para los proyectos de extensión-proyección social. En Bogotá, se seleccionaron las localidades donde se encuentran ubicadas las sedes de la Universidad siendo Barrios Unidos (Quinta de Mutis en el barrio Siete de Agosto), La Candelaria (Claustro), Mártires (Meredi-Hospital Universitario Mayor) y Usaquén (Sede Norte) a nivel micro". ${ }^{31}$

Para lograr este objetivo se está fortaleciendo la relación con los diferentes actores locales de las zonas de influencia, entre estos la Alcaldía Local, Consejos de Cultura, Casas de la Cultura, artistas, artesanos y organizaciones culturales entre otros. En los años 2008-2009 se desarrollaron las siguientes acciones: planeación, diseño y concertación de ferias locales de emprendimiento cultural; establecimiento de acuerdos de trabajo con los gestores culturales; realización en septiembre de 2009 del VII Encuentro de la Red Nacional de Extensión, donde se presentó la experiencia de formulación del plan de cultura de la Universidad de Antioquia por parte de María Adelaida Jaramillo; clúster del Turismo La Candelaria; sensibilización con ediles y alcaldes locales del Distrito y apoyo logístico al Consejo Local de Arte, Cultura y Patrimonio de la localidad de La Candelaria.

31 UNIVERSIDAD DEL ROSARIO, DIRECCIÓN DE EXTENSIÓN. Informe de gestión 2008, p. 3. 


\section{Eventos y actividades realizadas desde la Dirección de Desarrollo Humano de la Dirección Administrativa y de Tecnología}

Bajo el concepto de salud ocupacional y bienestar se desarrollan programas dirigidos al personal administrativo de la Universidad. Como parte de ellos están las actividades recreativas y culturales que se realizan en conjunto con las cajas de compensación familiar, así como programas de turismo nacional e internacional, subsidios de vivienda y educativo. ${ }^{32}$ (Ver cuadro 8 ).

\section{Equipamientos e infraestructura}

La Universidad del Rosario cuenta con escenarios polivalentes para la circulación de productos artísticos y culturales. Se destacan, en el Claustro, el Aula Máxima, el Aula Mutis, el Teatrino y la capilla de La Bordadita, esta última con una destacada acústica. En cuanto a equipamientos para creación en artes, la Universidad ha acondicionado espacios en la Casa Reynolds (plásticas, música) y en el Palacio San Francisco (danza). Si bien estos espacios resultan insuficientes y no tienen las condiciones óptimas, se han hecho esfuerzos importantes en cuanto a las dotaciones para realizar estas prácticas.

\section{Percepciones sobre el rol de la cultura y el arte en el proyecto universitario}

El grupo de la comunidad educativa con el que se trabajó más sistemáticamente fueron los estudiantes. A ellos se les aplicó un cuestionario con preguntas abiertas y que fue contestado y discutido en grupos focales por un total de 317 estudiantes entre los meses de abril y mayo de 2009. La información obtenida se encuentra en proceso de sistematización para presentar

32 UNIVERSIDAD DEL ROSARIO, Boletín estadístico 2009. 


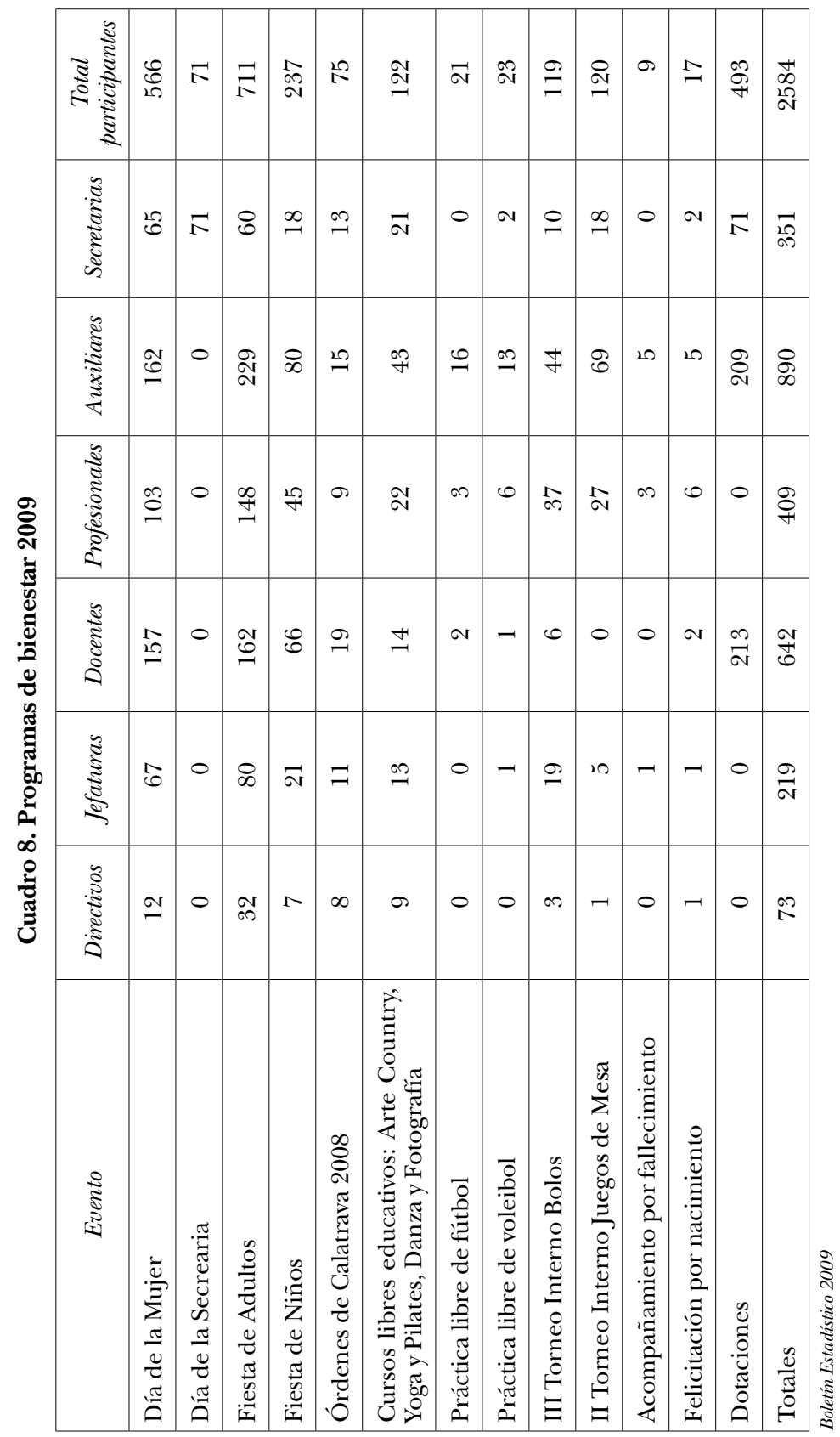


los resultados de manera agregada, pero vale la pena resaltar ciertos aspectos.

Los principales hallazgos fueron:

- Mayoritariamente los estudiantes perciben la cultura como aquello "que distingue a un grupo de otro", y como "expresión de una comunidad" y las diferentes "maneras de interpretar el mundo". También relacionan la cultura con tradición, raíces, identidad e historia y finalmente como reglas, hábitos y comportamientos de un grupo.

- En relación con la cultura rosarista, mencionaron algunos rasgos que para ellos la caracterizan: cumplimiento de las reglas (normas), respeto, honestidad, responsabilidad, puntualidad, solidaridad, compañerismo, liderazgo. También la asocian con el patrimonio y símbolos de la Universidad: La capilla, el claustro, la estatua del fundador y con la historia, la tradición política, el número de presidentes de la República egresados de la universidad y con el orgullo que sienten por pertenecer a la institución.

- Los estudiantes practican y participan en variadas actividades que incluyen deportes (tenis, squash, yoga, natación, ultimate, fútbol, equitación, basketball, rugby, automovilismo, ir al estadio) y la gimnasia. Actividades espirituales como ir a la iglesia. Recreación, juegos de rol, "comer fuera de casa", "salir con amigos", "viajar por la ciudad”, “conocer Bogotá antigua”, hacer turismo. En cuanto a la programación asociada específicamente con las artes se destaca, en primer lugar, la música y asistir a conciertos y a festivales como Rock y Jazz al Parque. Le siguen el teatro y el cine. Con una 
frecuencia más baja: televisión, visitar museos, lectura, pintura, dibujo, fotografía, danza y cantar.

Con base en la encuesta aplicada en 2007 a los estudiantes que ingresaron ese año al pregrado, ${ }^{33}$ se encontró que el $64,5 \%$ manifiesta practicar algún deporte y que el 35,7\% no practica ninguno. De los que sí practican, el fútbol es el de mayor puntaje. Se incluyeron las fiestas dentro de los hábitos de recreación y descanso, y el 66,4\% contestó que en el último mes había asistido máximo a cinco rumbas.

En relación con los estudiantes de postgrado la encuesta aplicada en 2009 arrojó la siguiente información:

- $\mathrm{Al} 69 \%$ de los estudiantes de postgrado les gusta asistir a actividades culturales, siendo mayor este porcentaje en las mujeres con un $71 \%$ y $66 \%$ en los hombres. A los que más les gusta asistir a actividades culturales tienen de 36 a 40 años de edad con un $77 \%$.

- Sobre las actividades culturales en las que les gustaría participar: teatro $48 \%$, cine $41 \%$, danza $26 \%$ y talleres o charlas $20 \%$.

- Dentro de las actividades que los estudiantes realizan en su tiempo libre se destacan: estar en familia, ver

33 Para el estudio de 2007 (pregrado) la muestra estuvo conformada por 658 estudiantes entre un universo de 1001 que ingresaron a primer semestre, lo que corresponde a un $65,7 \%$ que estaban presentes en el momento de la aplicación del instrumento. El promedio de edad de los estudiantes es de 18 años, comprendidos entre los 14 y 36 años. El 6,5\% tiene menos de 17 años, el $71,9 \%$ está entre 17 y 18 años y el $20.7 \%$ es mayor de 18 años. "Con el fin de observar comportamientos de los estudiantes por rangos de edad el estudio planteó discriminar los menores de 17 años como estudiantes con edad baja, entre 17 y 18 con edad media y mayores de 18 con edad alta”. 
televisión, navegar en internet, leer, ir al cine, salir a pasear y dormir.

- $\quad$ El 86\% de los estudiantes practica deportes; se destacan: caminar, ir al gimnasio, fútbol, natación y ciclismo.

- A un 33\% de los estudiantes les gustaría participar en estas actividades los sábados de $12 \mathrm{~m}$ a 5 pm; a un $17 \%$ les convendría asistir a estas actividades de lunes a viernes de 6:00 am a 8:00 pm; a un 14\% los domingos de 8:00 am a 5:00 pm.

\section{Marco de acción de la política cultural}

En la Universidad del Rosario la política cultural aborda tres debates que resultan fundamentales para la definición del marco que le dará sentido a las acciones. El primero tiene que ver con la definición misma de política cultural, cuestión que remite necesariamente al debate sobre la cultura como categoría de intervención y, finalmente, ambas discusiones se contextualizan a la naturaleza y fines de la institución universitaria en general y de la Universidad del Rosario específicamente.

\section{Políticas culturales: debates y definiciones}

Es posible identificar al menos tres corrientes con relación a las políticas culturales. Los estudios culturales ${ }^{34}$ han venido cobrando gran relevancia desde los años noventa en Colombia

34 Los estudios culturales son una disciplina que desde los años ochenta se ha venido investigando y que ha generado una importante literatura sobre las transformaciones contemporáneas del arte y la cultura. Si bien es un grupo bastante heterogéneo, los estudios culturales se han venido consolidando desde los años setenta principalmente en Gran Bretaña y Estados Unidos, descubriendo "nuevas áreas y campos enteros de la cultura popular, de los medios de comunicación de masas" y poniendo "a prueba los métodos para explorarlos” (BARKER, Martin y BEEZER, Anne. Introducción a los estudios culturales. Barcelona: Bosch, 1994, p. 7). 
y América Latina y hoy son varios los programas universitarios, asociaciones y redes existentes. ${ }^{35}$ Con relación a las políticas culturales se destaca el trabajo de la investigadora colombiana Ana María Ochoa Entre los deseos y los derechos. Un ensayo crítico sobre las políticas culturales, ${ }^{36}$ que es una buena guía para aproximarse a la multiplicidad de trabajos y a las diferentes miradas sobre las políticas culturales desde los estudios culturales.

Ochoa define "como política cultural la movilización de la cultura llevada a cabo por diferentes tipos de agentes -el Estado, los movimientos sociales, las industrias culturales, instituciones tales como museos u organizaciones turísticas, asociaciones de artistas y otros- con fines de transformación estética, organizacional, política, económica y/o social". ${ }^{37}$

En un segundo grupo tenemos las definiciones construidas desde diversas instituciones públicas y de carácter multilateral, que buscan de cierta manera "estabilizar" la discusión desde la legitimidad de cada entidad. Germán Rey, en su contribución al compendio de políticas culturales del Ministerio de Cultura de Colombia Las políticas culturales en Colombia: la progresiva transformación de sus comprensiones, ${ }^{38}$ señala algunas de las definiciones que considera relevantes. La Unesco, como organismo

35 En los años setenta se rechazaba la idea de ser "un cuerpo cerrado e internamente convalidado de conocimientos e ideas". Se valían libremente de la literatura, la sociología, los estudios de filmes, la psicología (especialmente el psicoanálisis), la teoría política, antropología, etc. También fue muy destacada su vinculación con movimientos sociales tales como organizaciones socialistas, feministas, antirracistas, artísticas y de cultura local (ver: Baker \& Beezer, op. cit., p. 8).

36 OCHOA, Ana María. Entre los deseos y los derechos. Un ensayo crítico sobre políticas culturales. Bogotá: ICANH, 2003.

37 Ibid., p. 20.

38 COLOMBIA, MINISTERIO DE CULTURA. Compendio de Políticas Culturales. Documento de discusión 2009, p. 23-42. 
del Sistema de Naciones Unidas encargado de la educación, la ciencia y la cultura, ha promovido la discusión y el posicionamiento del tema en la agenda pública de los países miembros a través de encuentros regionales, conferencias y publicaciones. En 1982 definió las políticas culturales como "el conjunto de principios, prácticas y presupuestos que sirven de base para la intervención de los poderes públicos en la actividad cultural, radicada en su jurisdicción territorial, con el objeto de satisfacer las necesidades sociales de la población, en cualquiera de los sectores culturales". ${ }^{39}$

En Colombia, Rey destaca otros ejemplos institucionales sobre el tema que, valga la pena resaltar, tienen su origen en procesos liderados por entidades de carácter subnacional. El Instituto Distrital de Cultura y Turismo de Bogotá, hoy Secretaría Distrital de Cultura, Recreación y Deporte, trabajó en el año 2003 en el marco del Sistema Distrital de Cultura el documento Políticas Culturales Distritales 2004-2016, que "entiende por políticas culturales el resultado de la concertación entre los sectores sociales en torno a los aspectos logísticos, políticos, económicos y sociales del campo cultural". ${ }^{40}$ El otro caso es el Plan Nacional de Cultura (2006-2020) "Antioquia en sus diversas voces" que define que "las políticas culturales se concretan bajo la forma de enunciados que indican el deber ser de dichas intervenciones, bajo un criterio permanente de concertación y participación democrática en el desarrollo cultural de las colectividades". ${ }^{41}$

En el tercer grupo se encuentra la perspectiva desde el análisis de las políticas públicas que confluyen en el estudio

39 Ibid., p. 28.

40 Ibid.

41 Ibid., p. 29. 
de The policies. ${ }^{42}$ Desde sus orígenes en los años cincuenta en los Estados Unidos el análisis de las políticas públicas ha buscado hacer aportes desde diferentes disciplinas al estudio y comprensión de la acción del Estado, es decir, sobre "cuáles facetas de la gestión de lo colectivo son asumidas por cuáles autoridades -políticas o administrativas-, locales o nacionales, de qué manera, en respuesta a cuáles problemas, a través de qué modalidades concretas, y suscitando cuáles consecuencias y por qué”. ${ }^{43}$ Hay que reconocer que la producción sobre las políticas culturales en general no es muy abundante, pero en Colombia es prácticamente inexistente. ${ }^{44}$

Ahora, si bien son pocos los contactos entre estas tres corrientes, es posible encontrar como punto de encuentro central entre ellas el reconocimiento de que la cultura, ${ }^{45}$ si bien está

42 Designa el proceso por el cual son elaborados y puestos en marcha los programas de acción pública, es decir los dispositivos político-administrativos coordinados en principio alrededor de objetivos explícitos.

43 Thoening en: GRAWITZ \& LECA. Traite de Science Politique. Paris: Presse Universitaire de France, 1985, p. 9.

44 Los trabajos que existen sobre las políticas culturales son en su mayoría recopilaciones o compilaciones de documentos institucionales, memorias de coloquios o seminarios y manuales de gestión cultural. Evidentemente, y si bien abordan el tema de la intervención pública en la cultura, no pueden considerarse como ejemplos de investigación desde el análisis de las políticas públicas. Para citar algunos: MENA \& HERRERA. Políticas culturales en Colombia. Discursos estatales y prácticas institucionales. Bogotá: M \& H Editoras, 1994; GÓMEZ, Rocío del Socorro, et al. Gestión cultural 1 y 2. Bogotá: Univalle, Convenio Andrés Bello, 2000; CONVENIO ANDRÉS BELLO. Economía y cultura. La tercera cara de la moneda. Memorias. Bogotá: Convenio Andrés Bello, 2001; INSTITUTO DISTRITAL DE CULTURA Y TURISMO. Políticas culturales urbanas. Experiencias europeas y americanas. Bogotá: Instituto Distrital de Cultura y Turismo, 2003; COLOMBIA, MINISTERIO DE CULTURA. Compendio de Políticas Culturales. Documento de discusión 2009.

45 La construcción social de la cultura como categoría de interven- 
ligada a los desarrollos en la ciencias sociales, ${ }^{46}$ es un proceso de construcción social y en el que confluyeron diversos actores o agentes públicos y privados tales como el Estado, administradores, grupos o asociaciones artísticas, movimientos sociales, funcionarios, académicos.

\section{Entrada y salida al debate sobre la cultura}

Abordar la discusión sobre las políticas culturales lleva necesariamente a encarar el debate sobre el concepto de cultura que está en juego.

Es recurrente en este tema citar a Kroeber y Kluckhohn, antropólogos estadounidenses que se dieron a la tarea de investigar las diferentes acepciones de cultura y encontraron 160 nociones sin adjetivo entre 1781 y 1950, lo que los llevó a afirmar que esta es una de las nociones clave del pensamiento americano contemporáneo, "comparable a categorías como gravedad en física, enfermedad en medicina o la evolución en biología". ${ }^{47}$

Este antecedente es un indicador de la importancia del concepto de cultura como objeto de estudio en las ciencias sociales pero también es manifestación de que su uso generalizado lleva implícita una alerta sobre todo en ejercicios de formulación de políticas. Pareciera que su sola mención sería suficiente para comprender y explicar una gran variedad de fenómenos y las dimensiones sobre las cuales intervenir para solucionar los problemas sociales contemporáneos.

ción es desarrollada, para el caso francés, por: DUBOIS, Vincent. La politique culturelle. Genèse d'une catégorie d'intervention publique. Paris: Belin, 1999.

46 CUCHE, Denys. La notion de culture dans les sciences sociales. Paris: Édition La Découverte, 1996.

47 KUPER, Adam. Culture. The antropologist's account. Cambridge, Massachusetts: Harvard University Press, 1999. En español: KUPER, Adam. Cultura. La versión de los antropólogos. Madrid: Paidós, 2001, p. 12. 
Varios autores desde diferentes disciplinas y algunos ejercicios de formulación de políticas comparten esta preocupación y han buscando ofrecer salidas. Los une el convencimiento que desde el punto de vista epistemológico la cuestión no se resuelve "pensando en plantillas alrededor de la noción de cultura o refinando las definiciones". ${ }^{48}$

Adam Kuper desde la antropología considera que es aconsejable evitar semejante término hiperreferencial (cultura) y hablar con mayor precisión de conocimiento, creencia, arte, tecnología, tradición o incluso ideología (aunque este concepto es igualmente problemático). Reivindica entonces a la etnografía como método privilegiado para describir y explicar de qué prácticas estamos hablando cuando hablamos de cultura. Desde la historia cultural ${ }^{49}$ se encuentran posturas cercanas a la de Kuper. Martín Lienhard ${ }^{50}$ apunta a poner de manifiesto la incapacidad de las teorías para explicar el fenómeno cultural por efecto del desconocimiento de factores circundantes como son religión, música, medicina, prácticas sociales y demás. Más bien de lo que se puede hablar es de ciertos códigos culturales que terminan por verterse en determinados espacios, territorios, sociedades o instituciones.

Por su parte, Sidney W. Mintz ${ }^{51}$ explica que las interpretaciones de la cultura no son jamás completas ni definitivas,

48 Ibid., p. 12-13.

49 Aporte de Radamiro Gaviria, profesor de Cátedra Rosarista en la Universidad del Rosario y quien elaboró el documento de trabajo "Formas Culturales”, en donde aborda la discusión sobre el concepto de cultura.

50 LIENHARD, Martín. Cultura andina y forma novelesca. Zorros y danzantes en la última novela de Arguedas. Lima: Editorial Horizonte/Tarea, 1990 .

51 MINTZ, Sidney W. (ed.). History, Evolution, and the Concept of Culture: Selected Papers by Alexander Lesser. Cambridge: Cambridge University Press, 1985. 
sino que resultan útiles en la medida en que den sentido a los hechos, estableciendo o demostrando interrelaciones entre los sujetos y su entorno. Debe advertirse sobre los cambios específicos de los grupos en las diversas sociedades, antes que pretender homogeneizar y generalizar en busca de un carácter común.

En igual sentido, el profesor Mauricio Pardo plantea cómo el concepto mismo de cultura nos encierra en un círculo vicioso de argumentaciones y contra argumentaciones, y resalta la vigencia de la definición de Néstor García Canclini en el texto sobre políticas culturales (1989), donde evita usar la palabra cultura y prefiere hablar de políticas, de intervenciones en la producción y de constitución de lo simbólico. ${ }^{52}$

En consecuencia, la política cultural de la Universidad del Rosario no va a definir "lo que es o no es cultura" y tampoco va a pretender zanjar las diferencias entre las distintas aproximaciones teóricas. Más bien la cultura se va a entender como un conjunto de prácticas de los diversos sectores, actores y grupos que constituyen la comunidad universitaria y que a través de ella se expresan, crean, se apropian del patrimonio y definen formas de convivencia. ${ }^{53}$

\section{Políticas culturales universitarias}

El primer aspecto para resaltar es la legitimidad de las universidades para formular políticas culturales y el deber que tienen de participar activamente en la discusión e investigación sobre las políticas públicas.

52 Intervención realizada en el foro ¿Por qué una política cultural? Organizado por la mesa Ascun-Cultura, el 8 de septiembre de 2009. Trascripción realizada por Héctor Delgado, p. 19.

53 Esta aproximación se sustenta en: COLOMBIA, INSTITUTO DiSTRITAL DE CULTURA Y TURISMO DE BOGOTÁ. Políticas Culturales Distritales 2004-2016. Bogotá: IDCT, 2005, p. 35. 
Ahora se justifica aún más el proceso de formulación de políticas culturales puesto que "la cultura en la Universidad, como una agenda de programación de actividades paralelas al proyecto educativo, enfrenta hoy una afortunada crisis" ${ }^{\prime 4} \mathrm{de}$ la que se colige que se debe ir más allá de las bellas artes y de los eventos, y "que no podemos circunscribir el tema cultura universitaria a simplemente las manifestaciones artísticas que tenga la universidad e incluso (...) únicamente a la programación de unos cuantos festivales, como lo veníamos haciendo" ${ }^{55}$

Así, por la vía de las políticas y la búsqueda de la pertinencia del proyecto universitario, entendida esta como "la adecuación entre lo que la sociedad espera de las instituciones y lo que éstas hacen", ${ }^{56}$ se llega necesariamente:

(...) a repensar el lugar que ocupa la cultura en la educación superior en cuanto a las relaciones que deben tejerse entre la formación, la investigación y la extensión con la cultura, la participación de las instituciones de educación superior en el desarrollo de los territorios, la re-

54 NIÑO MORALES, Santiago. Universidad: arte, cultura y patrimonio en un contexto de ciudad. En: DÍAZ TÁMARA, Adriana y GUZMÁN BEJARANO, Margarita. Universidad y cultura: reflexiones sobre políticas culturales. Bogotá D.C., 2010, p. 23-29.

55 Intervención de Carlos Ramírez en el foro ¿Para qué una Política Cultural en las Universidades? realizado por la mesa Ascun-Cultura, nodo Bogotá. Universidad Militar Nueva Granada, septiembre 8 de 2009. Transcripción de Héctor Delgado, p. 3.

56 Declaración Mundial de la Unesco sobre la Educación Superior en el siglo Xxi, citada en "Fundamentos para la construcción de una política cultural para educación superior en Colombia”, documento de trabajo preparado por la Mesa Cultural de Instituciones de Educación Superior de Antioquia para el Encuentro Nacional de Instituciones de Educación Superior: hacia la construcción de una política cultural (Medellín, 20 y 21 de junio de 2008), p. 8. 
definición de los procesos culturales institucionales que garanticen la pertinencia del proyecto cultural universitario, y la contribución de la educación superior al mejoramiento de las condiciones de vida de las comunidades, en cumplimiento de su responsabilidad social. ${ }^{57}$

Existe consenso al afirmar que "la Universidad es en sí misma un fenómeno cultural" 58 y que "el proceso formativo y educativo de la Universidad es esencialmente un proyecto cultural (...). Si bien no toda la cultura tiene lugar en la Academia, claramente es un lugar determinante para la socialización, valoración y legitimidad de las manifestaciones culturales" ${ }^{59}$ El reto que se deriva de este supuesto es que la cultura debe hacerse explícita en los currículos de los programas académicos, en la investigación que realiza la institución y en la extensión. Igualmente debe pensarse en la "cultura universitaria", ${ }^{60}$ es decir en aquellos hábitos, actitudes y percepciones que orientan los comportamientos de las personas que la conforman.

\section{Organización y nivel operativo de la política cultural}

La política se entiende como "un marco general de acción que moviliza valores, conocimientos y comportamientos, así como instrumentos de acción particulares con miras a realizar los

57 Ibid., p. 10.

58 REY, Germán. Cultura e interculturalidad en la universidad. En: DÍAZ, Adriana y GUZMÁN, Margarita. Universidad y cultura. Bogotá: Universidad del Rosario, Decanatura del Medio, 2010, p. 43.

$59 \quad$ NIÑO. Op. cit., p. 24.

60 Ibid., p. 25-26. 
objetivos construidos en los intercambios entre actores (...)" ${ }^{61}$ Las acciones de la política se sustentan en las relaciones establecidas entre los diferentes grupos y las unidades académicas y administrativas que conforman la comunidad universitaria y que intervienen en la cultura en la Universidad. Por esta razón la política hace de la participación, la concertación y el intercambio entre ellos un aspecto central de su proceso de construcción, implementación y seguimiento.

La parte sustancial u operativa de la Política Cultural de la Universidad del Rosario se organiza a través de un objetivo general, programas y proyectos que definirán los lineamientos o cursos de acción que serán desarrollados en adelante.

\section{Objetivo general}

Crear las condiciones para fortalecer la cultura rosarista, estimular la creatividad y las prácticas artísticas, las expresiones culturales y del patrimonio de quienes componen la comunidad universitaria, reconociendo estas como aspectos fundamentales del medio universitario y de los estilos de vida que sustentan el subprograma Universidad Promotora de Salud.

\section{Programas y proyectos}

Un programa es un conjunto de proyectos que buscan una finalidad u objetivo general común. Como parte del programa cada proyecto se ejecuta de manera independiente pero se articula con los demás proyectos en el cumplimiento del objetivo del programa. Un proyecto es un conjunto de actividades que

61 MULLER, Pierre et SUREL, Yves. L'Analyse des politiques publiques. Paris: E. Montchrestien, Clefs/Politique, 1998. (Existe la edición en español) 
se realizan de forma concatenada para la consecución de un objetivo y donde se concretan las metas y recursos.

Cuadro 9. Política cultural: programas y proyectos

\begin{tabular}{|c|c|c|}
\hline PROGRAMAS & & PROYECTOS \\
\hline $\begin{array}{l}\text { Fortalecimiento } \\
\text { de la cultura } \\
\text { rosarista }\end{array}$ & $\rightarrow$ & $\begin{array}{l}\text { 1. Proyecto Ideas la representación y lo sim- } \\
\text { bólico en el Rosario } \\
\text { 2. Proyecto de Cultura Ciudadana } \\
\text { 3. Proyecto Cultura y Participación } \\
\text { 4. Proyecto en Valores }\end{array}$ \\
\hline $\begin{array}{c}\text { Vive la cultura } \\
\text { universitaria }\end{array}$ & $\rightarrow$ & $\begin{array}{l}\text { 1. Proyecto de apoyo a las prácticas artísticas } \\
\text { y culturales } \\
\text { 2. Proyecto de información en arte y cultura }\end{array}$ \\
\hline $\begin{array}{l}\text { Patrimonio } \\
\text { cultural } \\
\text { e identidad } \\
\text { rosarista }\end{array}$ & $\rightarrow$ & $\begin{array}{l}\text { 1. Proyecto Museo Virtual } \\
\text { 2. Proyecto de Circulación del Patrimonio } \\
\text { Cultural de la Universidad del Rosario } \\
\text { 3. Proyecto Formación no formal en Patrimo- } \\
\text { nio Cultural de la Universidad del Rosario }\end{array}$ \\
\hline $\begin{array}{l}\text { Programa } \\
\text { de extensión } \\
\text { cultural }\end{array}$ & $\rightarrow$ & $\begin{array}{l}\text { 1. Proyecto Territorios y Patrimonio } \\
\text { 2. Proyecto de Arte y Ciudad } \\
\text { 3. Proyecto Diversidad e Interculturalidad } \\
\text { Local } \\
\text { 4. Proyecto de Gestión Cultural }\end{array}$ \\
\hline
\end{tabular}

